\title{
The Influence of Teamwork on the Performance in International Joint Venture
}

\author{
Danmeng Feng ${ }^{1}$, Xiaoyuan $\mathrm{Chu}^{1}$, Weiwei Chen ${ }^{1}$ \\ ${ }^{1}$ School of Public Management, Beijing University of Posts and Telecommunications, Beijing, China \\ Correspondence: Danmeng Feng, School of Public Management, Beijing University of Posts and Telecommunications, \\ Beijing, China.
}

Received: April 28, 2016

Accepted: May 12, 2016

Available online: June 14, 2016

doi:10.11114/aef.v3i4.1675

URL: http://dx.doi.org/10.11114/aef.v3i4.1675

\begin{abstract}
This paper makes an empirical study on whether the influence of teamwork on IJV performance is relatively positive or negative. Aiming to make a more accurate and comparative analysis, the research utilizes the method of questionnaire survey among three kinds of companies which are all located in China, which are local companies、Sino joint ventures and foreign companies. Based on several dimensions which make significant influence in team work, this paper uses factor analysis and correlation analysis by SPSS to arrange the data gaining from the questionnaire survey. By comparing the result of IJV with the other two kinds of companies, the thesis will propose the final conclusion.
\end{abstract}

Keywords: teamwork, performance, sino-joint ventures

\section{Introduction}

With the highly increasing competitiveness and more complicated work, there are more companies apply teamwork as their management style. Based on some previous research, teamwork is represented to be a significant factor to improve a company's performance. Organizational leaders and managers are convinced that collaborative teamwork is an effective tool to manage complex tasks in a rapidly changing world (LaFasto \& Larson, 2001); Management has increasingly viewed the organization of workers in teams as a tool to increase productivity (Spreitzer et al., 1999); Boning, Ichinowski and Shaw (2007) find that team-based work is associated with 6\% higher firm productivity, especially in the case of complex products; Teams can make better decisions than individuals (D. Purg L. Isabella P. Casse P. Caudel H. Kenfelj, 2003). But there are still some potential negative factors in teamwork for the improvement of performance. Until now, there are numbers discussions about the influence of teamwork in companies. Standing on the point of employees, working in a team generally means a higher pace of work and working to tight deadlines both in the new and old EU Member States. Moreover, it is reasonable to assume that increased work intensity and work pressure have a negative impact on employees' health.( Renáta Vašková, 2007); Also Kandel and Lazear (1992) argue that worker involvement through teams may generate mutual monitoring and increased peer pressure ( Kandel, E., Lazear, E., 1992). This research will focus more on the influence of teamwork on international joint venture, standing on the point of developing countries. Because of the nationality differences and culture diversity among the IJV members, it is more controversial and complicated to appraise the influence of teamwork on IJV is positive or negative.

In 1994, Stephen P. Robbins fist proposed the definition of "teamwork": the formal group which is composed by the mutual cooperation of individuals to achieve a certain goal. In the later decades, the definition of "teamwork" is utilized comprehensively in many areas. In the research of Hoegl \& Gemuenden(2001), team work was defined as a social communication in a team, including the internal action, interaction and emotion. Based on the Denison Culture Model, which is built by Denison (1995), team work is a significant factor of cooperate culture which influence the company's performance.

In recent years, there is a highly increase of economic development and foreign investment in developing countries. By entering the 21th century, the world is faced more and more problems on globalization, the increasing links between national economies makes high dependence among all countries around the world and more and more countries began to put a high investment to foreign countries. From 1970s, the growth rate of international investment is higher than the growth rate of international trade. According to the report of United Nations Conference on Trade and Development, the number of foreign direct investment in 1999 increased 55.2\% higher than which in 1998, up to $\$ 8650$ billion, until 2000 , 
the number of global foreign direct investment has achieved a new record up to 13,000 billion. From 2001 to 2005, the total number of global foreign direct investment is 44,000 billion, which is much higher than the total number in 1996 2000. Based on the previous practice, the most universal and frequent international investment is among United States, European countries and Japan, with the development of global economics and the increasing competitiveness in developing countries. Except the trade among developed countries, the economical benefits between developing and developed countries began to connect closer and influence each other. Many developing countries put more percentage of investment on developing countries and cooperate with local companies in developing countries. Taking China as the case in this paper, China began to bring in private investment from foreign countries in 1979 when the country started to pursue the policy of opening up to the outside world (Edward Yui-tim Wong, 1998). By agreeing to the terms of its accession to the WTO, especially after the financial crisis, there is an intensified pressure on the local companies in China, but at the same time, it brings some large opportunities to the country's economic competiveness and openness to the global market. More and more multinationals search for opportunities in China to make cooperation and until now large numbers of Sino-foreign joint ventures have been built in China. By the end of 1993, the number of Chinese-Foreign equity joint ventures and Chinese-foreign contractual joint ventures registered in PRC were 107,820, and 25,500 respectively ( Ming Pao Daily News, 1994). However, as a main form of investment, Sino-foreign joint ventures are widely utilized, but the final performances are not satisfied as we expected. According to some previous researches, the authors agree that the culture conflicts make a great threaten on the IJV performance. And also there are numbers of researches propose that the main factor lead IJV to failure or poor performance is culture conflicts (Cartwight S, et al. 1993). Based on the Denison Culture Model (Siew Kim Jean Lee, Kelvin Yu, 2004), the thesis will focus specifically on teamwork which is a composition of culture differences for IJVs. In the last decade, the use of teamwork has become widespread in organizations such as project team, production team, quality circles, management teams, and self-managing teams.

Cross-cultural research suggests that cultural values will influence the willingness and ability to work in teams (James W. Bishop, Xiangming Chen, K. Dow Scott). Also in Hofstede's Culture dimensions, the dimension of individualism vs. collectivism promotes that "the degree to which individuals are integrated into groups" (Bengt-Arne Vedin Eskiltuna, Sweden, 2007). Because teams are collective entities, this dimension is important to any studies of how cultural values influence employees' orientation toward teamwork.

According to the collection of many previous researches about the connections between culture differences and company's performance, there is a controversial discussion on the evaluation of culture differences. Most of the researches are based on the four dimensions in Denison Culture Model. In Tian Hui's research about the relationship between cooperation culture conflicts and performance in Sino-Chinese joint ventures, he concludes that totally saying, the conflicts in every dimension of culture model all have a negative influence on the performance. In JING Run-tian and LUO Yu-shu's research, they conclude that different dimensions lead to different research conclusions. The culture differences have a positive impaction, while emotional conflicts have a negative impaction on the organizational effectiveness.

The objective for this paper is to evaluate the influence of teamwork on the Sino-foreign JV performance based on culture dimension. This evaluation should be done by comparing with the teams in foreign companies which is located in China and domestic companies.

Before doing the research, there are four hypotheses made to forecast the relationship between the factors of teamwork and team performance when on the basis of culture dimension. In this research, Sino-joint ventures are mainly studied.

$\mathrm{H}$ 1: There is a closer relationship between teamwork factors and team performance in Sino-joint ventures than other kinds of companies based on culture dimension.

Based on the background of culture difference, the factors of the operation of teamwork also make a different level of roles on the final performance in these three kinds of companies. Focusing on the Sino-joint ventures, the motivation for this research is mainly to find out whether the relationship between teamwork and team performance is relatively more crucial than other two kinds of companies. The first hypothesis is made to predict that based on the culture dimension, the teamwork factors have a relatively more crucial effect on the final performance in Sino-joint ventures.

$\mathrm{H}$ 2: There is a lower relationship between teamwork factors and team performance in Sino-joint ventures than other kinds of companies based on culture dimension.

The second hypothesis is made mainly to predict that the teamwork factors play a relatively less important role for the final performance in Sino-joint ventures. The motivation is to elaborate that with the culture difference in Sino-joint ventures, the teamwork has a lower correlation with the final performance than the other two kinds of companies.

H 3: All these three kinds of companies have a close relationship between teamwork factors and team performance based on culture dimension. 
The third hypothesis mainly reflects that no matter for which kind of companies, the teamwork all have close relationships with their performance. This can indicate that the culture aspect plays a role in promoting the relationship between teamwork and performance for all kinds of companies.

H 4: All these three kinds of companies have a low relationship between teamwork factors and team performance based on culture dimension.

On the contrary, the last hypothesis is that the teamwork in all kinds of companies has less crucial effect on their final performance. The motivation is to indicate that on the culture aspect, the relationship between teamwork and performance is not very close for all the companies. It also indicates that the culture dimension plays a less important role for the correlation between teamwork and performance.

\section{Factors of Teamwork Which Influences the Company Performance}

Teamwork has become an important part of organizational working culture to the extent that organizations now make teamwork skill part of the necessity for employment (Owolabi A. B, 2012). The aim of teamwork was to improve working conditions and rationalization. Based on the International Joint Ventures, teamwork can be defined as a group of individuals brought together from more than one functional area of a business to work on a problem or process, which requires the knowledge, training and capabilities across the areas to successfully complete the work (Xin Shen, 2002). Because the influence of culture difference is mainly represented on the internal dimension of company, so the traits of "involvement" and "consistency" take more important role (M. Shakil Ahmad, 2012). The core topic "teamwork" utilized in this thesis is derived from the analysis of Denison Culture Model, which is the result of over twenty-five years of research by Dr. Daniel Denison, focusing on the link between organizational culture and bottom-line performance measures such as return on investment, sales growth, quality, innovation and employee satisfaction (Ismael Younis Abu-Jarad), The Denison model measures four critical traits of culture and leadership, there are mission, adaptability, involvement, and consistency. According to some previous researches on the components of culture difference and their influence in IJV, the factor which is included in the culture difference is selected on this thesis as a main object of research, because teamwork is an important and a controversial factor connecting to the final performance. According to the above research by $\mathrm{Li}$ xiaohui, as a conclusion, the variable of teamwork represents a media mark to influence IJV's performance when comparing with other variables (Liu, Min, Larsen, Erik, Wezel, Filippo Carlo).

Based on the various definition of teamwork, it can be influenced by several main element, different researches have made various kinds of elements for a team based which they focus on. Some researches apply one of the best team process taxonomies, which is found in Dickinson et.al where "seven key components of teamwork" that have a major effect on group behavior and functioning are identified from a survey of the team performance literature. They are communication, feedback, leadership, team orientation, backup, monitoring and coordination (Mike Winter, 2004).

Comparing with the previous researches and focusing on the main topic "culture dimension" in this paper, there are four main characteristics which can influence the teamwork's performance and function can be analyzed. They are team communication, team trust, team encouragement and support,and team creativity.

\subsection{Team Communication}

Communication is the main foundation for all team functioning. What is team communication? Simply saying, team communication is any form of communication among members of the same group or organization that is crucial for a healthy and effective dynamic. Many frustrations, misunderstandings and questions can easily be addressed with the proper team communication.

For example, a message isn't communicated unless it has been understood by the recipient. The bilateral communication and feedback are the answers in the process of communication. The feedback tells to the transmitter that the recipient has understood the message, the importance level of it and what to do with him (Ioan Bordean1, Alina Răileanu, 2009). It requires that all team members cooperate to establish ongoing communication with each other, aiming to develop a more harmonious team environment and more effective performance. Team communication also includes the exchange of information and opinions, language communication, the share of project-related information and reliability among members. It is a very crucial feature for a team to function effectively and dynamically.

A healthy team communication can help eliminate many misunderstand and frustrations which develop within the team. It is thus essential to learn on improving team communications to address misunderstanding and to improve team efficiency. And a healthy team communication can increase the quality and level of team, which can also increase the trust among team members.

In contrast, an inharmonious team communication can lead team conflicts and make a barrier for gaining higher and more effective performance. For example, a communication in one team which lacks of sharing information frequently 
can make a blocking working atmosphere and discourage the utilization of information. Also this kind of situation can decrease the trust and reliability among team members. Also the problem of language in team takes a considerable role, especially in IJVs. Working in cross-cultural teams, there are great challenges to all the team members. One obvious problem that can arise is the language communication. When the team members speak different languages they have trouble communicating. Sometimes, the differences create conflict, miscommunication, and diminished productivity. The conflicts of language communication can direct influence the understanding among team members and the effectiveness of working.

\subsection{Team Trust}

Team trust is another core factor which influences the team performance. In recent years, there are many researched have studied the team trust, based on the different perspectives, there are also various definitions about team trust. Generally speaking, trust has been defined as a confident belief or expectation and as a willingness or intention to depend on the trustee, (the person truster places trust) (Natasha Dwyer, 2011). On the perspective of awareness and expectation, Morgan and Hunt also propose that trust is one partner has enough confidence on the other partner's dependability and honesty (Marcia L. Watson, 2005). Trusting beliefs involve perceptions that the other party will act in ways favorable to then truster (Boon, S.D. and J.G. Holmes,1991), or that the other party has ethical, efficacious, or favorable characteristics (Michael H. Dickey, D. Harrison McKnight, 2010) On the perspective of willingness and behavior, trust can be defined as based on one party has the ability to monitor or control the other party, the party prefers to give up this ability while put themselves in the situation with exposed weakness and the risk of being damaged by the other party.

Team trust is built on the basis of many direct and potential factors. Based on the individual perspective, the most director factor which influence team trust is members' ability, which includes the professional knowledge, the ability of solving problems, coordination capacity and so on. The members' high level of ability can increase others' confidence and dependability so that there can be a closer relationship and more frequent cooperation among members, which can increase the team trust. This point can also represent that team trust has a significant influence for the long term development of teams.

When based on the team perspective, team trust is influenced by the effectiveness of leadership. It is the most basic phenomenon for the presence of the team leader, because an effective team requires the cooperation of every task, the clear definition of every member's role in the team, and the quick and correct decisions for the team. Even if team members have already a relatively high level of autonomy, they still require a clear objective and direction made by leaders, and also they need leaders to maintain their working processes and conditions. A team lacking of effective leadership and well coordination relationship can lead the team objective unclear, and without direction. Under thus condition, members can hardly build trust to other members and also the team, because a unclear objective can directly decrease the performance and team level, which can discourage team members' confidence and trust. So an effective leadership has a positive influence on the team trust.

There is another factor based on the team perspective which is called member heterogeneity. When focusing on the team creativity, it is certain that the more difference among team members can encourage team to connect more opinions, ideas, resource of knowledge and the solution of resolving problems, and also it can increase the team's creativity. But while focusing on the team trust, it can be a controversial factor, especially for IJVs, some researches propose that the member heterogeneity has a positive impact on the team trust. They have noted that while a team with high level of similarity of knowledge, background, nationality, it can lead a closer interpersonal relationship among members, which is always followed with more frequent unhealthy activities with conflicts, jealousy, misunderstanding and so on. All these are barrier to build trust. In contrast, a team with high level of heterogeneity has the structure of members with different professional skills and behavior to coordinate together. The questions and different opinions created among members are also based on the view of profession and work requirement but not on the view of personal preconception or personality. This phenomenon can help avoid some conflicts among members and can make the team trust easier.

But some researches propose the opposite opinions that the team heterogeneity has a negative influence on team trust. Based on the different nationalities, different languages and culture background, first it can directly influence the team communication, which is a key basic step to build trust. For example, the members certainly prefer to communicate with one with the same language than another one with different language, because it is much easier and convenient to talk and understand, and also it is easier to make a closer personal relationship with the members with the same language. So a closer relationship among members can encourage them to understand others better, and then it will be much easier to build trust. Although a closer relationship may lead some conflicts with personal problems, anyway this situation is relatively better than a team with a team lacking of communication. Also team members with different nationalities have large gaps on attitudes and beliefs, which are potential barriers for members to communicate and 
cooperate. So member heterogeneity has a negative influence on team trust.

\subsection{Team Support and Encouragement (Team Spirit)}

Team spirit is defined as the spirit of a group that makes the members want the group to succeed. Team spirit is about supporting one team, respecting others and most of all encourage the team mates. It is the basic step of leadership. According to some studies, the team spirit is the result of integration of four processes [28Nicolescu \& Verboncu, 1997]:

1) Building the trust between the involved people;

2) Establishing of a mission and of some clear goals at which the persons are joining

3) Retracing of participatory decision-making processes;

4) Strong motivation, individual of the group, to contribute to achieve the common goals.

Actually saying, team spirit is to achieve the above processes. It can be analyzed into two dimensions, one dimension is between members and members, the other dimension is between leaders and members. The primary step to build team spirit is trust. It is necessary for team members to trust all their colleagues, their leaders, in order to trust their team. Based on the member to member dimension, the trust can be built by both themselves and the leader's management. For example, as it is mentioned in "team trust", the most direct factor which influences team trust is members' ability, which includes the professional knowledge, the ability of solving problems, coordination capacity and so on. If the team members have a high ability in professional knowledge and practical working experience, it is easier for their colleagues to trust. Also standing on the point of leaders, they can make some policies about increasing the openness and share of team resources. This can decrease members' wariness and Jealousy to each other, as well it can increase their enthusiasm to help and support their colleagues. While based on the leaders-members dimension, leaders make a critical role in building the team spirit for all the team. Leadership tasks in a group include providing direction, support, structure and the clarification of team goals for members of the group. According to past researches, the behavior and communication of leaders and managers in the organization is critical to whether staff will behave ethically (Summary report, 2000).

1). Staffs are more likely to do what they see their supervisor and particularly their senior managers doing than to adhere to ethicalpolicy (Andrews, 1989).

2). The most important determinant of unethical behavior is the behavior of managers (Lysons, 1989, in Badenhorst, 1994).

It can be represented that the leaders make the most important role on the support and encouragement for the staffs.

\subsection{Team Creativity}

The research of creativity has been studied since many years ago, until now, it has a significant development. The creativity research was primary studied from the view of psychology in 1950 with the famous creativity lecture by Guilford. J.P Guilford's 1950 address to the American Psychological Association inspired the now-thriving field of creativity research. The true genius of Guilford's contribution was the ability to specify the vague but in triguing notion of creativity according to distinct constructs that define individual creative thinking. (David A. Hardcastle, Patricia R. Powers, Stanley Wenocur, 2004) With the studying for half of century, there is a high development on creativity. Totally speaking, there are simply four Ps for the definition of creativity: Person, researching the characteristics of people with high creativity; Product, investigating which kind of product has a high level of creativity; Process, the process of building creativity; Press/Place, investigating which kind of press or place is conducive to build creativity. Although the research of creativity has been developed, most research and writing on creativity the "long genius," with little recognition of the social and group factors that influence the creative process (Ashford C. Chea, 2009).

Until now, there is still no agreement on the definition of "creativity". In primary research on team creativity, people always focus on the individual members in team, which they think individuals are the main factor to influence the team creativity. There have been already many researches proposing that the difference of individual's creativity can influence the team creativity. But with more different views have be put in the team creativity research such as social dimension, psychological dimension and environmental dimension, based on these dimensions, researchers found the problem that most previous researches lack of attention to team factors in the field of creativity. Isolation and individual reflection were often regarded as the key factors in creative accomplishments (Paul B. Paulus, Bernard A. Nijstad, 2003). And also the literature searches in the mid-1990s mentioned few conditions of team creativity. It began to focus more attention on the external factors for the team creativity such as social and atmosphere factors. And except the individual factor which influences team creativity, the study based on the view on "team" is also necessary to take into account, such as the structure of team, the team tasks, the team background, the team objective, and the team leadership and so on. According to some researches on the evaluation of team creativity, the conclusion contributed by all previous 
studies is that the team creativity is not the simply addition of individuals' creativity, also it can be influenced by some factors based on the view of "team". It can be reflected in innovation processes in teams. Innovation process, including product development and commercialisation, is nowadays concurrent and team based. It cannot be structured simply as a sequential process where one functional area hands off outputs to the next. Neither can the process be structured as a set of parallel activities, where each functional area works independently of the others (Conny Heebert Antoni, 2005).

\section{Research Study Methodology}

\subsection{The Mode of Research}

Because this paper applies the subjective measure to do the research, the data used by the subjective measure cannot be collected by public resources. Therefore questionnaire survey is employed as the mode of research in this paper. For the analysis on receives questionnaire, the SPSS statistical software is applied to make a quantitative analysis.

\subsection{Sample Selection and Data Sources}

This paper selected 200 office workers who are working in 30 teams from three kinds of companies which are mainly located in Shanghai, China. There are 10 teams from domestic companies, 10 teams from foreign companies and 10 teams from Sino-foreign joint venture located in China. All the companies selected are middle size and the teams are mainly from market sector which are relatively more flexible and have more demand for members' cooperation and interaction. The companies selected in this research involve mainly three dimensions: the first one is manufacturing, such as iron and steel manufacturing and automobile manufacturing; the second one is service sector, such as foreign trade and IT service; the third dimension is construction industry.

\subsection{Questionnaire Design}

The content of the questionnaire in this paper is based on the vertical and horizontal analysis for the whole frame about teamwork and performance. The questionnaire is built by the integration of some relative researches with questionnaire and some private opinions. The aim is to represent comprehensively all the indicator of teamwork and team's performance. This paper mainly applies Gringer's subjective measure on team performance. There are two indicators of the manager's evaluation for achievement of the company's strategic objectives. One focuses on efficiency, the other is the team competitiveness.

In this paper, there are two kinds of questionnaire made for all the teams. One is the questionnaire for team members, which is built following the indicators of teamwork measuring. The other questionnaire is made for managers in one team, this represent the final situation of team performance. Also it follows the indicators of team performance measuring.

In the questionnaire for members, it concludes 13 questions which represent the four main factors influencing the operation of teamwork. The questionnaire for team performance includes five questions for managers in one team. The answer for all these questions are made based on the five-point Likert scale,

\subsection{Data Collection}

By sending questionnaire to 30 teams in three kind of companies mainly located in Shanghai, China, which are selected with medium size and in market sector. Totally there are 180 questionnaires have been sent, and 155 questionnaire have been received. The response rate of questionnaire is $86.1 \%$, which is high, because most questionnaire are sent face to face which is relatively more effective to be received. After deleting useless questionnaires, finally the number of effective questionnaire is 120 .

Based on the 5-point Likert scale, there are five answers for every question which represents the levels of the worst、 worse、neutral、 better、 best. And following with the different levels, every answer can be matched with the scores from 1 to 5 .

\section{Factor Analysis of Teamwork and Performance Indicators.}

\subsection{Factor Analysis of Teamwork and Company Performance Indicators.}

By using factor analysis, each dimension of team work involves several indicators. Firstly, team creativity includes five indicators which are mainly reward system of team members' innovation, The diversity of the team members, The team members' discussion, The members' adoption from peers' advise and The frequency of the parties made for team members. The result is shown below: 
Table 1. Factor Analysis Result of Teamwork Indicators

\begin{tabular}{ll}
\hline Factor & Content of variable \\
\hline 1 & V9:The reward system for team members' innovation \\
Team & V10: The diversity of the team members \\
Creativity & V8: The team members' discussion for every new task in team \\
& V5: The members' adoption from peers' advise \\
& V12: The frequency of the parties made for team members \\
\hline 2 & V1: Information communication among team members. \\
V2:Language communication among team members \\
V13: The team managers' fairness behavior \\
\hline 3 & V3: The task sharing among team members \\
Team & V6:The system about reward and punishment for team members \\
Spirit & V7: Team members' assistance to other peers \\
& V2: Language communication among team members \\
\hline 4 & V11: The percentage of believers in team \\
Veam trust & V4: The reliability of information transformed in team
\end{tabular}

With the same method to make factor analysis for company performance, the result combine the two dimension (efficiency and competitiveness) together, the result shows below:

Table 2. Factor Analysis Result of Company Performance Indicators

\begin{tabular}{ccc}
\hline NO. & Indicators of Team Performance Measuring \\
\hline Efficiency and Competitiveness & Entering to the market and be rewarded \\
& The reduction of capital investment \\
& $\begin{array}{c}\text { The reduction of competitiveness } \\
\text { Research and development }\end{array}$ \\
\hline
\end{tabular}

\subsection{Reliability and Validity Analysis.}

Reliability is another important method which is the fact that a scale should consistently reflect the construct it is measuring (Dr, Andy Field, 2005). Actually reliability aims at testing whether the measurement is stable. When after making a scale or questionnaire, the first step is to do reliability test to ensure its reliability and stability. The simplest and most effective way to do the reliability analysis is using Cronbanch's alpha, which is a coefficient named by Lee Cronbach. Until now, Cronbach's alpha is the most common measure used to ensure the internal consistency or reliability of a test core in a sample. Especially in researches of psychology, also in the field of social dimension, business and nursing.

Cronbach's alpha is defined as the equation as:

$$
\mathrm{a}=\frac{\mathrm{K}}{\mathrm{K}-1}\left(1-\frac{\sum_{\mathrm{i}=1}^{\mathrm{K}} \delta_{\mathrm{Y}_{\mathrm{i}}}^{2}}{\delta_{\mathrm{X}}^{2}}\right)
$$

Where $\mathrm{K}$ is the number of components or items, $\delta_{\mathrm{X}}^{2}$ is the variance of the observed total test scores, and $\delta_{\mathrm{Y}_{\mathrm{f}}}^{2}$ is the variance of component $i$ for the current sample of persons. 
The value of Cronbach's alpha represents the overall reliability of the selected scale, for general exploratory studies, the value in researches is enquired to reach at least 0.6.

By using SPSS tool, this paper applies Cronbach's alpha to test the sample classified as table 3 which is based on factor analysis:

By testing each subscale's alpha in SPSS, we can get each subscale's reliability. The result of teamwork shows as follow:

Table 3. The Reliability Result of Teamwork Indicators

\begin{tabular}{cccc}
\hline & \multicolumn{2}{c}{ Reliability Statistics } \\
\hline & \multicolumn{2}{c}{ Cronbachs Alpha } \\
& \multicolumn{2}{c}{ Based on standardized } \\
& Cronbach's Alpha & items & N of items \\
\hline team creativity & .612 & .608 & 5 \\
team communication & .606 & .605 & 3 \\
team spirit & .572 & .583 & 4 \\
team trust & .660 & .654 & 2 \\
\hline
\end{tabular}

From the table above we can see the value of Cronbach's alpha for the four dimensions are 0.612, 0.606,0.572and 0.660, the overall result is reliable, only the dimension of "team spirit" is a little lower than the criteria. The main reason linked is the number of selected items in this scale is too little. Also there is another possibility of a reason considered is some indicators included in this scale have the lower reliability so that they can influence the final scores.

With the same way wo got the reliability result of company performance, the result is below:

Table 4. The Reliability Result of Company Performance Indicators

\begin{tabular}{ccc}
\hline & Reliability Statistics \\
\hline & Cronbachs Alpha & \\
Cronbach's Alpha & Based on standardized items & N of items \\
.734 & .736 & 5 \\
\hline
\end{tabular}

From the table we can see the value of alpha is 0.736 , representing a high reliability.

\subsection{Factor Score of Teamwork Indicators}

Based on the generally analysis for SPSS output, it mainly talks about the comparison of initial classification of teamwork and the new classification made by SPSS for all the companies. It also explains the shift of these 13 indicators. In this part, with the final result of factor score made by SPSS, the research will calculate the four factor score respectively for these three kinds of companies and make a horizontal comparison during the companies.

In this research, there are totally 90 items are being measured for the questionnaire survey which concludes 13 indicators. The first one to the thirtieth items are local companies; the thirty-first to the sixtieth items are Sino-joint ventures which this research mainly focuses on; the last thirty items are foreign companies. According to the five factor scores on every item made by SPSS, which applies the regression method, the average factor score for every kind of companies can be calculated based on the equation: $\mathrm{Fv}_{\text {average }}=\left(\mathrm{Fv}_{\mathrm{n}}+\mathrm{Fv}_{\mathrm{n}+1}+\mathrm{Fv}_{\mathrm{n}+2}+\ldots+\mathrm{Fv}_{\mathrm{n}+29}\right) / 30$;

"F $\mathrm{V}_{\text {average }}$ " represents the average factor score for one kind of companies which includes thirty companies;

"v" represents the No. of factor which is included in the four extracted factors;

" $n$ " represents the No. of the item in questionnaire.

Also aiming to integrating the scores of the four single common factors and make a synthesized evaluation, the comprehensive score can be calculated based on the equation: $\mathrm{F}=\left(15.289 \times \mathrm{F}_{1 \mathrm{k}}+14.659 \times \mathrm{F}_{2 \mathrm{k}}+14.516 \times \mathrm{F}_{3 \mathrm{k}}+12.021 \times \mathrm{F}_{4 \mathrm{k}}\right) / 56.485$;

"k" represents the kind of company. (Local company 、 Foreign company or Sino-joint venture)

So table 5 shows the final scores for every common factor and their rankings. As follows: 
Table 5. The Factor Score of Teamwork Indicators

\begin{tabular}{|c|c|c|c|c|c|c|c|c|c|c|c|}
\hline & $\begin{array}{l}\text { F1 } \\
\text { creativity }\end{array}$ & Team & Ranking & $\begin{array}{c}\text { F2 Team } \\
\text { Communication }\end{array}$ & Ranking & $\begin{array}{c}\text { F3 } \\
\text { Team } \\
\text { Spirit }\end{array}$ & Ranking & $\begin{array}{c}\text { F4 } \\
\text { Team } \\
\text { Trust }\end{array}$ & Ranking & $\mathrm{F}$ & Ranking \\
\hline Local Company & -.31310 & & 3 & .15998 & 2 & 60249 & 1 & .30475 & 1 & .18 & 1 \\
\hline $\begin{array}{l}\text { Sino-Joint } \\
\text { Venture }\end{array}$ & .42971 & & 1 & -.69960 & 3 & -.45882 & 3 & -.26350 & 3 & -.24 & 3 \\
\hline $\begin{array}{l}\text { Foreign } \\
\text { Company }\end{array}$ & -.11661 & & 2 & .53963 & 1 & -.14368 & 2 & -.04124 & 2 & .06 & 2 \\
\hline
\end{tabular}

From table 5 it shows these three kinds of companies' scores on team creativity (F1)、 team communication(F2)、 team spirit(F3)、 team trust(F4) and comprehensive factor(F), also with their respective rankings.

First is the comparison of single factors on teams in these companies. For the aspect of team creativity, the Sino-joint ventures are the highest, the foreign companies are medium, local companies remain the last.

For the team communication part, instead teams in Sino-joint ventures have the lowest score. Because of the more complex structure of organization in Sino-joint ventures, such as the different nationalities for the partners v the different ownership structures, all these can make a negative influence for the team's communication. According to the data collected, the possibility from $30 \%$ to $61 \%$ for companies which cannot make a relationship of cooperation or their relationship will be faired in 5 years (Osborn, 2003). One of the main reasons is communication barriers, including the language communication、 information communication、the view communication during the company's operation. Analyzing to practice, for example, in the 1980s, China began to make policies to be open for transnational corporations. A number of multinational companies entered and made cooperation with domestic companies. However, actually their corporation as Sino-joint ventures did not beneficial, because they partners haven't shared the same strategy, with the inconsistent management in both parent companies and different opinions for investment inside cooperation team, which lead to the communication barrier for the partners. While based on the team members' communication after Sino-joint venture has been built, the members included are mainly from two parts, Chinese members and foreign members. The basic problem linked is the language barrier for communication. Although English as the international language can be used among members, it is relatively more inconvenient and less effective for them to use a second language to express their own opinions. The last point which influences the Sino-joint ventures' communication is the members' share of information. In the processes of producing and managing by both collaborators, based on the different point of views and policy decisions, it will lead interest conflict among partners, especially when one of them behaves relatively more outstanding than other, the members in less outstanding part faces more threats for their interest. With this unequal strengths and positions, the members' information cannot be shared completely to their peers from the other partner. As conclusion, all these conflicts because of the structure of Sino-joint ventures can restrict the communication in its team.

Another important factor is team spirit, which is also a crucial indicator to reflect one team's ability of coordination. Since the communication score for Sino-joint ventures are much lower than other two kinds of companies, so for this indicator, it definitely has a negative effect on team spirit. Another indicator to increase the encouragement and cohesion among members is the managers' leadership. An explicit direction of leadership and management can give members a clear objectives during their working. While in Sino-joint ventures, they also have the problems for the consistency of leadership. Because of the different percentages of each partner's control authority for their company, there are many conflicts for the partners aiming at achieving the profit maximization. It is unrealistic to get the maximal profit on both partners, for each partner, it is inevitable for them to make lots of conflicts during gaining a consistent management. This also can influence the team's coordination and encouragement for others.

For the team trust factor, local companies behave the best among these three, Sino-joint ventures is still the last on this factor. This situation can be liked with the culture characteristics. In China there is one proverb called "Better safe than sorry", from this we can see based on thounsands of Feudal Government, the closed mental and psychological preparedness are fused in Chinese and they are difficult to be changed. So facing the partners they do not know well, it is relatively more difficult for them to lay down their vigilance and make a communication with full trust. While based on the same nationality, it can be easier to behave the full trust to their peers and managers. 


\section{Correlation Analysis and Result}

\subsection{Correlation Analysis between the Teamwork Indicators and Company Performance .}

According the calculations of factor analysis and reliability analysis respectively for the teamwork indicators and team performance indicators, focusing on teams in Sino-joint ventures by comparing with local companies and foreign companies located in China. This part integrates the teamwork indicators and team performance based on the culture dimension.

Correlation is applied to test the level and strength of association between variables. In this part, the purpose of using correlation test is to test on the culture dimension, what about the degree of each factor of the operation of teamwork with the team performance in Sino-joint ventures located in China. Also test the correlations in local companies and foreign companies located in China by comparing with the Sino-joint ventures.

Table 6. The Correlation Result of Teamwork and Company Performance

\begin{tabular}{llccc}
\hline & Local company & $\begin{array}{c}\text { Sino-joint Venture } \\
\text { performance }\end{array}$ & $\begin{array}{c}\text { Foreign Company } \\
\text { Performance }\end{array}$ \\
\hline Vperformance & Pearson Correlation & 1 & 1 & 1 \\
& Sig.(2-tailed) & & & \\
V1 & $\mathrm{N}$ & 30 & 30 & 30 \\
Team Creativity & Pearson Correlation & $.522^{* *}$ & .112 & .151 \\
& Sig.(2-tailed) & .003 & .554 & .424 \\
V2 & $\mathrm{N}$ & 30 & 30 & 30 \\
Team Communication & Sig.(2-tailed) & .226 & -.165 & .069 \\
& $\mathrm{~N}$ & .230 & .384 & .718 \\
V3 & Pearson Correlation & 30 & 30 & 30 \\
Team & Sig.(2-tailed) & .175 & .015 & -.034 \\
Spirit & $\mathrm{N}$ & .355 & .938 & .856 \\
V4 & Pearson Correlation & 30 & 30 & 30 \\
Team & Sig.(2-tailed) &. .102 & $.441^{*}$ & .091 \\
Trust & $\mathrm{N}$ & .590 & .015 & .632 \\
V5 & Pearson Correlation & $.475^{* *}$ & 30 & 30 \\
comprehensive factor & Sig.(2-tailed) & .008 & .153 & .142 \\
& $\mathrm{~N}$ & 30 & .421 & .454 \\
& $\mathrm{~N}$ & & 30 & 30 \\
\hline
\end{tabular}

*.Correlation is significant at the 0.05 level (2-tailed).

**. Correlation is significant at the 0.01 level (2-tailed).

Focusing on the correlations between teamwork factors and team performance factors shown in table above. First looking at the correlations for Sino-joint ventures which are mainly studied in this paper. The factor of team trust has the strongest positive correlation with team performance (with the correlation coefficient as 0.441 ), also the correlation is significant. Comparing with the same factor in the other two kinds of companies, the correlations between team trust and team performance are lower than which in Sino-joint ventures. This indicates that team trust has a relatively stronger correlation with the final performance in sino-joint ventures. Trust between partners is suggested to be an important factor that contributes to the success of IJVs (Inkpen and Currall, 2004). The higher level of trust for the partners in Sino-joint ventures, the easier for them to exchange knowledge. So that can directly influence the information sharing and communication in the team. Therefore it reflects that in Sino-joint ventures, team trust is a relatively more crucial factor to impact the final performance than which in other kinds of companies.

Another particular factor is team communication. In local companies and foreign companies, the correlation between team communication and team performance is positive. While in Sino-joint ventures, it is negative (but insignificant). Because of the more complex structure of Sino-joint ventures, it can be more difficult to ensure an active communication for the companies' operation. At least in the psychological aspects, the team members in Sino-joint 
ventures have more insecurity while communicating the working information with foreign peers, which can directly influence team communication. Also they are more cautious for the external environment (location), in this paper, it is China. In China, Sino-joint venture began to increase quickly just in thirty years ago, the economic development is so fast that other elements such as culture、 education cannot catch on. So that with the less diverse culture background, there are many potential problems exists for the numbers of Sino-joint ventures' building. Team communication is one of them being influenced. Also when focusing on the communication for team managers in Sino-joint ventures, because of the different culture backgrounds for these managers, there is a big difference in their interpersonal relationship and management style. For example, standing on the point of China, foreign managers focus more on the information of line managers, while Chinese managers are more dependent on social norms. So this can easily make problems during their interpersonal communication. Overall observing, based on the culture difference's influence, the correlation between the comprehensive factor(V5) and team performance in Sino-joint ventures is positive as 0.153 , but is not significant. the local companies have a strongest correlation (0.475) between the comprehensive factor and team performance significantly. While foreign companies and Sino-joint ventures both have the lower correlations insignificant. It can be understood easily that the local companies have the advantages on their locations communications and team innovation, though on the team trust aspect, it has a less crucial effect, however, the comprehensive factor has a more crucial influence on team performance than others. So it can be indicated that for the teams in Sino-joint ventures, when based on the culture difference, the teamwork has a relatively less strong relationship with the final performance. While comparing Sino-joint ventures with foreign companies, it shows that the correlation between the comprehensive factor and team performance in Sino-joint ventures are closer than which in foreign companies. With this result, it can reflect that facing the barrier of culture difference, it may be a way for transnational investment in China to build the corporate relationship. The government also made a lot of policies to encourage the Sino-joint ventures' development in China, such as reducing the corporate income tax.

Making integration for all the results above, we can see while based on the culture dimension, the relationship between teamwork and team performance in Sino-joint ventures is lower than which in local companies, but higher than foreign companies. This indicates that for the teams in Sino-joint ventures, the teamwork has a less importance to influence their performance than which in local companies. With the culture difference in Sino-joint ventures, this dimension cannot improve the correlations between teamwork and performance. We can conclude that comparing with the local companies which has a less culture difference, the teamwork in Sino-joint ventures has a relatively less crucial effect on final performance. While comparing with foreign companies, the result in Sino-joint ventures is better. We can see that the teamwork in Sino-joint ventures plays a more important role than which in foreign companies. However, from the correlations for every single factor for all the companies, most correlation coefficients are low, representing most of the correlations are not strong. It can indicate that based on culture dimension, the teamwork has a relatively less significant influence on team performance.

Therefore according to the four hypotheses made in chapter two, the second hypothesis (There is a lower relationship between teamwork factors and team performance in Sino-joint ventures than other kinds of companies based on culture dimension.) and the fourth hypothesis (All these three kinds of companies have a low relationship between teamwork factors and team performance based on culture dimension.) are mostly in consonance with the final result of the research. Respectively observing Sino-joint ventures which is focused in this research, with the background of culture difference, the relationship between teamwork and the final performance is not less close than which in local companies, but a little closer than which in foreign companies. Overall looking at these three kinds of companies, the relationship of teamwork and final performance for them are all relatively low.

\section{References}

Abu-Jarad, I. Y. Yusof, N. A., \& Nikbin, D. (2010). A Review Paper on Organizational Culture and Organizational Performance. Centre for Promoting Ideas, USA, December.

Andrews, K. R. (1989). Ethics in Practice. Harvard Business Review, 99-104.

Badenhorst, J. A. (1994). Unethical Behaviour in Procurement: A Perspective on Causes and Solutions. Journal of Business Ethics, 13. http://dx.doi.org/10.1007/BF00881334

Baninajarian, N., Abdullah, Z. (2009). Groups in Context: A Model of Group Effectiveness. European Journal of Social Sciences , 8(2).

Bengt-Arne, V. (2007). Future's Trends: Culture vs. Institutions?. Transcultural Futurist Magazine, Vol. 6, no. 1, Spring.

Bishop, W. J., Chen, X. M., \& Scott, K. D. (1999). WHAT DRIVES CHINESE TOWARD TEAMWORK?. Southern Management Association annual meeting, Atlanta, October 27-30.

Boning, B., Ichniowski, C., \& Shaw K. (2007). Opportunity Counts: Teams and the Effectiveness of Production Incentives, Journal of Labor Economics, 25(4), 613-650. http://dx.doi.org/10.1086/519539 
Boon, S. D., \& Holmes J. G. (1991). 'The Dynamics of Interpersonal Trust: Resolving Uncertainty in the Face of Risk, Cooperation and Prosocial Behavior. 190-211.

Bordean, I., \& Răileanu A. (2009). Leadership within the organization. The Future Leaders. Euro Economic, 2(23).

Cartwight S., et al. (1993). The role of culture compatibility in successful organizational marriage. Academy of Management Executive, 7(2), 57-70.

Chea, A. C. (2009). Exemplary Models of Firm Innovation: Strategy and Leadership for the Twenty-First Century Competitive Environment. International business Research, April. http://dx.doi.org/10.5539/ibr.v2n2p9

Chen, X. H., \& Zhao, K. (2010). An Empirical Study of Team Conflict, Conflict Management and Performance. NanKai Business Review, 13(5), 31-35.

Conny, H. A. (2005). Effects of team structure on team climate for innovation and team out comes. University of Trier.

Dickey, H. M., McKnight, H., \& George, J. F. (2010). The Role of Trust in Franchise Organizations. European Journal of Economics Finance and Administrative Sciences, 18.

Dwyer, N. (2011). Traces of Digital Trust: An Interactive Design Perspective. Victoria University, March.

Fey, F. C., \& Denison, D. R. (2000). Organizational Culture and Effectiveness: The Case of Foreign Firms in Russia, SSE/EFI Working Paper Series in Business Administration, April.

Field, A. (2005). Reliability Analysis. Reaserch Method II, 2.

French, W. L., \& Bell, C. H. (1995). Organization Development: Behavioral Science Interventions for Organization Improvement. Englewood Cliffs, N. J. Prentice-Hall.

Geringer, J. M., \& Hebert, L. (1989). Control and Performance of International Joint Venture. Journal of International Business Studies, Summer. http://dx.doi.org/10.1057/palgrave.jibs.8490359

Habing, B. (2003). Exploratory Factor Analysis. University of South Carolina, October 15.

Hardcastle, D. A., Powers, P. R., \& Wenocur, S. (2004). Community Practice Theories and Skills for Social Workers. Second Edition.

Hoegl, M., \& Gemuenden, H. G. (2001). Teamwork Quality and the Success of Innovative Projects: A Theoretical Concept and Empirical Evidence. Organization Science, July/August 435-449. http://dx.doi.org/10.1287/orsc.12.4.435.10635

Hoegl, M., Parboteeah, K. P., \& Gemuenden, H. G. (2003). When Teamwork Really Matters: Task Innovativeness as A Moderator of The Teamwork-Performance Relationship in Software Development Projects. Eng. Technol. Manage, 281-302. http://dx.doi.org/10.1016/j.jengtecman.2003.08.001

Inkpen, A. C., \& Currall, S. C. (2004). The Coevolution of Trust, Control, and Learning in Joint Ventures. Organization Science, 15, September/October. http://dx.doi.org/10.1287/orsc.1040.0079

Kozlowski, S. W. L., \& Ilgen, D. R. (2006). Enhancing the Effectiveness of Work Groups and Teams. Psychological Science in the Public Interest, 6. http://dx.doi.org/10.1111/j.1529-1006.2006.00030.x

Lee, S. K. J., \& Yu, K. (2004). "Corporate culture and organizational performance", Journal of Managerial Psychology, 19(4),340 - 359. http://dx.doi.org/10.1108/02683940410537927

Li, H., Xu, L. Q., Zhou, Z. H., Zhang, L. J., Jin, Z. H., Lu, D., \& Li, J. (2003). Historical Immigrations to Shanghai Suburb Based on Principal Component Analysis on Physical characters and Surnames. Journal of Genetics and Molecular Biology, 14(4), 233-242, December 1.

Li, T. J., Tsui, A. S., \& Elizabeth, W. (1999). Management and Organizations in the Chinese Context. ST.MARTIN'S PRESS,INC, 270.

Liu, M., Larsen, E., \& Wezel, F. C. (2011). 'Robin Hood against The Big Four': Identity Processes And Market Partitioning, Organization and Management Theory Conference Paper.

Martins, E., \& Martins, N. (2002). An Organisational Culture Model To Promote Creativity And Innovation. SA Journal Of Industrial Psychology, 58-65. http://dx.doi.org/10.4102/sajip.v28i4.71

Ming Pao Daily News. (1994). "The Policy of Absorbing Foreign Investment in Mainland China.” April.

Nicolescu, O., \& Verboncu, I. (1997). Management, Ed. Economic, Bucharest.

Owolabi, A. B. (2012). Effect of Psychological Work Climate and Emotional Intelligence on Teamwork. Journal of Asian Scientific Research, 2(3), 150-158. 
Paulus, P. B., \& Nijstad, B. A. (2003). Group Creativity: Innovation through Collaboration. Oxford University Press. http://dx.doi.org/10.1093/acprof:oso/9780195147308.001.0001

Shakil, A. M. (2012). Impact of Organizational Culture on Performance Management Practices in Pakistan. Business Intelligence Journal , 5(1).

Shen, X. (2002). Factors Affecting Multifunctional Teams in Innovation Processes. Working Paper, 13, January.

Watson, M. L. (2005). Can There Be Just One Trust? A Cross-Disciplinary Identification of Trust Definitions and Measurement. The Institute for Public Relations.

What is an Ethical Culture (2000). Key issues to consider in building an ethical organization, 9.

Winter, M. (2004). Developing a Group Model For Student Software Engineering Teams. University of Saskatchewan.

Wong, E. Y. (1998). Factors Affecting Joint Venture Performance in China. Hong Kong Institute of Business Studies, June.

Zink, D. (2007). Learning Organizations: A Methodology for Organizational Effectiveness.

\section{(cc) $\mathbf{E Y}$}

This work is licensed under a Creative Commons Attribution 3.0 License. 